\title{
A presença de Friedrich Nietzsche na vida e na produção de Aldo Palazzeschi
}

\author{
Juliana Hass* \\ Adriana Iozzi Klein**
}

Resumo: As bibliotecas dos escritores com frequência fornecem detalhes em relação às suas produções, pois acabam por revelar e alargar a compreensão de algumas influências que, de modo geral, não seriam nítidas em suas obras; muitas vezes, são inspirações provenientes também do momento histórico, sobretudo naqueles que viveram em épocas de profundas transformações. Este artigo tem por objetivo mostrar a influência de Friedrich Nietzsche na vida e em parte das obras de Aldo Palazzeschi produzidas e publicadas na primeira metade do século XX.

Palavras-chave: Aldo Palazzeschi, Friedrich Nietzsche, futurismo italiano, biografia, biblioteca dos escritores, influência.

* Universidade de São Paulo (USP), São Paulo, SP, Brasil.

ORCID https://orcid.org/0000-0002-4114-7450

Correio eletrônico: juliana.hass@usp.br

** Universidade de São Paulo (USP), São Paulo, SP, Brasil.

ORCID https://orcid.org/0000-0003-0124-8297

Correio eletrônico: adriozzi@usp.br 
Hass, J. e Klein, A. I.

"Os poetas não vêm de outros poetas, mas sim da mãe terra, isto é, da vida que os exprime, após ter reabsorvido em si tantas coisas, inclusive os poetas anteriores" (Benedetto Croce a Emilio Cecchi, 11 de dezembro de 1911).

Fazendo um rápido balanço da crítica sobre o poeta e escritor florentino Aldo Palazzeschi, constatamos que as investigações mais promissoras dos últimos anos são as que exploram um território fronteiriço entre a biografia e a literatura, com o auxílio de instrumentos de outras disciplinas, como as artes plásticas, as artes cênicas e a filosofia, entre outras. Essa maneira de ler seus escritos é, ao mesmo tempo, mais interna a eles porque remonta às suas fontes, reconstruindo o clima intelectual no qual o autor estava inserido, e mais externa porque atenta às influências recíprocas, aos panoramas culturais e à visão cronológica do conjunto de sua obra.

Lembramos que o progresso dos estudos palazzeschianos vem incrementando o conhecimento também de aspectos da vida do autor até pouco tempo inacessíveis para a maioria dos pesquisadores. Os dados obtidos dos arquivos e das correspondências podem nos oferecer a possibilidade de ampliar as aberturas, as analogias e os paralelos entre as dimensões da experiência vivida e da elaboração literária do autor. Partindo dessa premissa, nosso objetivo neste estudo é mostrar a influência do pensamento de Nietzsche na vida e em parte das obras de Aldo Palazzeschi, produzidas e publicadas na primeira metade do século XX.

Em 1976, Fausto Curi, hoje professor emérito de Literatura Italiana Contemporânea na Università di Bologna, após apresentar o estudo I "buffi" o la fine dell'utopia no Congresso Palazzeschi oggi, realizado em Florença naquele ano, foi questionado por seus colegas "sobre a possibilidade de um escritor não muito culto como

1 «I poeti non vengono da altri poeti ma dalla madre terra, cioè dalla vita che li esprime, dopo avere riassorbito in sé tante cose ed anche i poeti precedenti» (Benedetto Croce a Emilio Cecchi, 11 dicembre 1911). Obs.: Todas as vezes em que não aparecer o nome do tradutor, significa ser livre tradução nossa para que o leitor, não proficiente em italiano, possa acompanhar o texto sem prejuízos.

202 | Cad. Nietzsche, Guarulhos/Porto Seguro, v.42, n.2, p. 201-222, maio/agosto, 2021. 
A presença de Friedrich Nietzsche na vida e na produção de Aldo...

Palazzeschi ter realmente lido Nietzsche e ter se aproveitado dessas leituras em seu trabalho"2 (CURI, 2007, p. 39). Muitos anos depois, em 2005, Curi volta ao tema e apresenta, em um congresso internacional realizado na Universidade de Bonn, os resultados de uma pesquisa intitulada Palazzeschi e Nietzsche, com a qual comprova que o autor não só havia realmente lido textos do filósofo alemão como também teria explorado profundamente essas leituras em seu trabalho.

Em 1906-um ano após iniciar sua carreira de poeta-, Palazzeschi toma emprestado os volumes Assim falou Zaratustra e Humano, demasiado humano na biblioteca do Gabinetto Scientifico Letterario G.P. Vieusseux de Florença, como atesta o registro do empréstimo revelado, em 2001, no álbum biográfico, Scherzi di gioventù e d'altre età. Album Palazzeschi (1885-1974), fruto do primoroso trabalho de organização do acervo pessoal do autor realizado por Simone Magherini.

Partindo de uma reflexão contextualizada em termos políticosocioculturais sobre a tradução - feita por Gabriele D’Annunzio ${ }^{3}$ - da palavra Übermensch para o italiano, Curi passa, então, a percorrer os principais escritores futuristas influenciados pela filosofia de Nietzsche até chegar a Palazzeschi. O estudioso analisa com atenção os temas da loucura; da "morte de Deus" - que, na verdade, em Palazzeschi aparece na representação de "um Deus totalmente humanizado e pelo qual o escritor demonstra nutrir simpatia sem, porém, qualquer reverência"4 (CURI, 2007, p. 55) -; da "transvaloração de todos os valores"; da leveza e, por fim, do "além do homem" presentes nos poemas La fiera dei morti, E lasciatemi divertire, Chi sono?, no manifesto Il Controdolore e no romance Il Codice di Perelà, todos escritos e publicados no início do século XX.

$2[\ldots]$ sulla possibilità che uno scrittore non molto colto come Palazzeschi avesse letto realmente Nietzsche e se ne fosse giovato nel suo lavoro.

3 Vale lembrar que seu filho, Gabriellino D’Annunzio, era amigo e colega de Palazzeschi na escola de arte dramática.

$4[\ldots]$ un Dio totalmente umanizzato e per il quale lo scrittore mostra di nutrire simpatia senza però alcuna riverenza"

Cad. Nietzsche, Guarulhos/Porto Seguro, v.42, n.2, p. 201-222, maio/agosto, 2021. | 203 
Diferentemente da proposta de Curi, tentaremos investigar a influência da filosofia de Nietzsche tanto na vida quanto nas produções do poeta e escritor, partindo de sua biografia e ancorando-a no contexto histórico da época. Obviamente, não há como, aqui, entender e explicar a transição do século XIX para o século XX e seu lugar na história, sobretudo por ter sido um período marcado por um processo de grande transformação revolucionária, como sustenta a conhecida tese de Hobsbawm (1988, p. 7) em A era dos impérios. Contudo, ainda que de maneira muito sucinta, gostaríamos de tentar localizar as raízes de Palazzeschi no passado e contextualizar a sociedade/ cultura de seu tempo, com o intuito de entender melhor sua produção poética e literária.

Estamos absolutamente de acordo com Gino Tellini, um dos mais importantes estudiosos de Palazzeschi na Itália, ao defender que:

[...] a exploração biográfica, desde que cuidadosamente orientada, pode ser útil para aprofundar a personalidade de um escritor e ponderar melhor o significado de seus textos. Pode ser útil pelo menos para quem considera a literatura não um exercício formal, um mundo ilusionista, um jogo de palavras, encerrado em si mesmo, mas uma forma de conhecimento sem precedentes da realidade, de modo a enraizar-se não apenas na geografia e na história (linguística, social, política, cultural: filosofia, arte, música, espetáculo), mas também na experiência vivida; [...]. O estudo da biografia é proposto como um conhecimento direto das experiências humanas, com a convicção de que esse conhecimento seja uma ferramenta necessária para melhor compreender autores, obras, textos individuais. Um instrumento, não um fim ${ }^{5}$ (Tellini, 2020, p. 73).

$5[\ldots]$ l'esplorazione biografica, purché accortamente orientata, può risultare utile per approfondire la personalità di uno scrittore e per meglio soppesare il significato dei suoi testi. Può risultare utile almeno per chi considera la letteratura non un esercizio formale, un mondo illusionistico, un gioco di parole, recluso in sé stesso, ma una forma di conoscenza inedita della realtà, tale da affondare le radici non solo nella geografia e nella storia (linguistica, sociale, politica, culturale: filosofia, arte, musica, spettacolo), ma anche nell'esperienza vissuta; [...]. Si propone lo studio della biografia come conoscenza in presa diretta di esperienze umane, con la convinzione che tale conoscenza è strumento necessario per meglio intendere autori, opere, singoli testi. Strumento, non punto di approdo.

204 | Cad. Nietzsche, Guarulhos/Porto Seguro, v.42, n.2, p. 201-222, maio/agosto, 2021. 
A presença de Friedrich Nietzsche na vida e na produção de Aldo...

Os últimos anos do século XIX até o início da Primeira Guerra Mundial foram marcados por acontecimentos políticos e sociais importantes, uma fase histórica configurada pela concretização de parte dos processos ideológicos e culturais e pelo surgimento de tendências que, posteriormente, se desenvolveram ao longo do século XX.

Do ponto de vista econômico, as medidas tomadas nas últimas décadas do século XIX resultaram em um processo que levou a Europa à "grande depressão", uma crise de enormes dimensões que sucedeu o período de forte crescimento, ocorrido entre os anos 1850 e 1873 e com efeitos positivos até 1896, quando a economia europeia entrou em um novo ciclo de expansão. $\mathrm{O}$ quadro de crise se caracterizou pela queda dos preços industriais e agrícolas, por uma estagnação geral da produção e por um forte aumento do desemprego. Diante deste cenário, os governos começaram a responder com uma série de medidas que, se por um lado tornaram os efeitos da crise mais toleráveis, por outro lado contribuíram para desencadear tensões e conflitos que pesaram ainda mais sobre o clima político e social europeu e mundial.

A primeira medida econômica implementada pelos países foi a do protecionismo, o fechamento de suas fronteiras aos produtos estrangeiros, em uma tentativa de salvaguardar a indústria e a agricultura nacionais, que passaram a operar em regime de monopólio e não de concorrência. Surgiram, assim, desequilíbrios nos setores de exportação que, ao terem os mercados tradicionais excluídos, mergulharam em uma profunda crise, não sendo mais capazes de reestruturar o mercado interno. Na tentativa de encontrar saídas para suas economias, além de oportunidades internas e de "escolhas culturais", os principais Estados europeus - França, Alemanha, Inglaterra, Itália, Bélgica, Holanda, Espanha e Portugal - adotaram uma política imperialista. Ademais, a cultura da época difundia o amor e o gosto pela guerra, pelo espírito de conquista e 
Hass, J. e Klein, A. I.

de poder nos diversos estratos sociais. Desse modo, mitos como o do "super-homem", racistas, irracionais e repletos de violência foram introduzidos no imaginário coletivo e constituíram o cenário cultural da Primeira Guerra Mundial.

Nesse contexto político-sociocultural, nasce (em 1885) e cresce Aldo Giurlani, poeta e escritor florentino, conhecido como Aldo Palazzeschi. Filho único de Alberto Giurlani e Amalia Martinelli, proprietários de uma loja de luvas e gravatas, estudou no Istituto Tecnico L.B. Alberti onde, em 1902, formou-se técnico de contabilidade. Seus pais queriam que o herdeiro prosseguisse com os estudos econômicos e comerciais, razão pela qual o matriculam na Reale Scuola Superiore di Commercio di Ca' Foscari. Entretanto, contrariando os planos dos pais, aos dezoito anos de idade, se inscreve na Regia Scuola di Recitazione: Tommaso Salvini, uma vez que a arte teatral era sua verdadeira paixão. Alguns anos depois, afasta-se do teatro e começa a dedicar-se, então, a sua carreira de poeta e escritor. Segundo Tellini (2020), embora afável, Palazzeschi era "rebelde, resoluto e duro". A homossexualidade o impulsionou a negar as normas convencionais, o fez sentir-se isolado e excluído, levando-o a entrar em conflito com a família e a pensar em suicídio. Palazzeschi, no entanto, como nos informa ainda o crítico italiano, passou por um processo de reflexão e, com isso, aprendeu a ignorar o julgamento dos outros, a ridicularizar os boatos e a libertar-se do conformismo. Esses dados - de natureza histórica, social e cultural - são, nas palavras de Tellini, "inevitáveis para compreender a peculiaridade da escrita de Palazzeschi" e ajudam a entender "a gênese de, pelo menos, cinco aspectos essenciais de toda a obra do escritor":

Primeiro: o cômico, a ironia, a paródia, implementados como ferramentas irreverentes e subversivas, que rompem a barreira fechada das ideias atuais e a prisão do conformismo [...]. Segundo: o tema do "diferente" (vivido por Aldo na própria pele) adquire absoluta centralidade, considerado em seus 
aspectos físicos, psicológicos, ambientais, e retratado nos mil obstáculos que o "diferente" deve enfrentar para a sua integração sempre árdua [...]. Terceiro: não se trata apenas de centralidade, mas também de positividade do "diferente", porque justamente ao "diferente" são confiadas a variedade e a complexidade da vida, mas também sua beleza, seu encanto, sua aventurosa imprevisibilidade, que a tornam única e iridescente [...]. Quarto: a arma da ironia e a promoção salutar do "diferente" resultam na capacidade de atribuir valor e significado inesperados, com pura sensibilidade criatural, ao "dom" da vida, aos aspectos simples, comuns, sinceros, inocentes da existência [...]. Quinto: aceitar a vida como um dom maravilhoso comum, natural, inevitavelmente fugaz (despido de qualquer egocentrismo individualista), significa aceitar com serenidade inclusive a morte ${ }^{6}$ (Tellini, 2020, p. 84).

Tais aspectos essenciais foram, ao que parece, reforçados também pelas leituras de Palazzeschi. O poeta e escritor florentino foi leitor de Nietzsche e, analisando sua biografia, parece inegável que o pensamento do filósofo alemão tenha influenciado também sua postura diante da vida. Ser "rebelde, resoluto e duro", negar as normas convencionais ao assumir-se homossexual, vivenciar um profundo e doloroso processo de reflexão e, com isso, aprender a desprezar o juízo alheio, a ironizar todo tipo de maledicência e a tornar-se assim um perene inconformista, nos mostram um pouco do "além do homem" nietzschiano cultivado em Palazzeschi.

Esses traços da filosofia de Nietzsche aparecem de forma bastante contundente no poema L'Incendiario considerado, a nosso

6 Primo: il comico, l'ironia, la parodia, messi in atto come strumenti dissacranti e sovversivi, che mandano in pezzi la barriera chiusa delle idee correnti e la prigione del conformismo [...]. Secondo: acquista assoluta centralità il tema del «diverso» (da Aldo sperimentato sulla propria pelle), considerato nei suoi aspetti fisici, psicologici, ambientali, e ritratto nei mille ostacoli che il «diverso» deve affrontare per la propria sempre ardua integrazione [...]. Terzo: non si tratta soltanto di centralità ma anche di positività del «diverso», perché proprio al «diverso» si affida la varietà e la complessità della vita, ma anche la sua bellezza, la sua attrattiva, la sua avventurosa imprevedibilità, che la rendono irripetibile e cangiante. Quarto: l'arma dell'ironia e la salutifera promozione del «diverso» hanno come esito la capacità di assegnare inaspettato valore e significato, con candida sensibilità creaturale, al «dono» della vita, agli aspetti semplici, comuni, schietti, innocenti dell'esistenza [...]. Quinto: accettare la vita come meraviglioso dono comune, naturale, inevitabilmente labile (spogliato di ogni egocentrismo individualistico), significa accettare con serenità anche la morte [...].

Cad. Nietzsche, Guarulhos/Porto Seguro, v.42, n.2, p. 201-222, maio/agosto, 2021. | 207 
Hass, J. e Klein, A. I.

ver, a mais emblemática declaração de poética de Palazzeschi, uma vez que apresenta uma estreita relação, explícita ou implícita, com várias outras de suas produções. Como justamente sustenta Bergman (2014, p. 241), “O poema reflete o super-homem nietzschiano $[\ldots]^{\prime \prime}$.

Publicado em março de 1910, na Edizioni Futuriste di «Poesia», L'Incendiario, composto por 249 versos livres, conta a história do incendiário. Os dez primeiros versos definem a situação poética que explica os fatos, mediante uma estrutura dialógica em que as falas caóticas e sem continuidade entre si se misturam e se confundem nas várias vozes do poema: o incendiário, enjaulado na praça da cidade por ter sido considerado irresponsável e perigoso, é ridicularizado, exposto aos comentários dos transeuntes: "No meio da praça central/ do vilarejo,/ foi colocada a jaula de ferro/ com o incendiário./ Ficará aí três dias/ para que todos possam ver./ Todos giram bem em torno/ da enorme jaula,/ durante o dia todo,/ centenas de pessoas"7 (Palazzeschi, 1910, p. 69).

Quem fala são os assim denominados conservadores, os defensores públicos da ordem e da respeitabilidade burguesas. Para eles, o incendiário representa a diversidade, que rejeita e quer destruir as falsas convenções de uma moral muitas vezes hipócrita e oportunista. Por isso, a polícia, representante do poder, o aprisionou, tornando-o objeto de reprovação e de escândalo, de curiosidade e de escárnio:

- Meu Deus, que descarado!/ - Mas que tipo de gente!/ - Eu o faria, de bom grado, em pedacinhos./ - Jogue-o no fosso!/ - Quero cuspir-lhe/ mais uma vez em cima!/ - Se o queimassem um pouco/ para que risse melhor!/ - Seria o fim que merece!/ - Quando estiver na prisão escapará,/ é tão astuto!/ - Pior que uma fuinha!/ - Não vêm que olhos ele tem?/ - Por que

7 In mezzo alla piazza centrale/ del paese,/ è stata posta la gabbia di ferro/ con l'incendiario./ Vi rimarrà tre giorni/ perché tutti lo possano vedere./ Tutti si aggirano torno torno/ all'enorme gabbione,/ durante tutto il giorno,/ centinaia di persone.

208 | Cad. Nietzsche, Guarulhos/Porto Seguro, v.42, n.2, p. 201-222, maio/agosto, 2021. 
A presença de Friedrich Nietzsche na vida e na produção de Aldo...

não o jogam num poço?/ - Na cisterna da prefeitura!/ - E tem quem/ que teria pena!/ - É preciso ser coisa imunda/ para ter compaixão/ deste tipo de gente! $^{8}$ (PALAZZESCHI, 1910, p. 72).

\title{
O público curioso, representado pelo coro de vozes, é interrompido pelo poeta:
}

\begin{abstract}
Abram caminho! Abram caminho! Abram caminho!/ Trastes! Pequenas criaturas/ que exalam fedor,/ fétido gado!/ Engulam todos vocês/ a sua bisbilhotice infame,/ e que se entale em suas gargantas!/ Abram caminho! Sou o poeta!/ Eu venho de longe,/ atravessei o mundo,/ para vir encontrar/ a minha criatura para cantar!/ Ajoelhe-se gentalha!/ Homens que têm horror do fogo,/ pobres criaturas de palha!/ Ajoelhem-se todos!/ Eu sou o sacerdote,/ esta jaula é o altar,/ aquele homem é o Senhor! ${ }^{9}$ (PALAZZESCHI, 1910 , p. 72-73).
\end{abstract}

Em seguida, após discursar sobre a repressão do mundo e o conformismo da massa, o poeta liberta seu prisioneiro:

Você me olha, sem falar,/ você não fala,/ e seus olhos me dizem:/ homem, pouco fará você além de conversa fiada./ Mas confio em você!/ Abro a jaula para você, vá!/ Veja, Veja como fogem!/ Estão insanos pelo horror,/ o medo enlouqueceu todos eles./ Podem ir, fujam, fujam,/ ele alcançará vocês!/ [...]/ Não as verei mais!/ Darei um grito de alegria!/ Você passou aqui!/ E depois sentirei minhas roupas sendo roçadas,/ as chamas arderão/ sob a minha casa.../ gritarei, exultarei,/ me terá dado a vida!/ Eu sou uma chama

8 - Dio mio che sfacciato!/ - Ma che sorta di gente!/ - Io lo farei volentieri a pezzetti./ - Buttatelo nel fosso!/ - Io gli voglio sputare/ un'altra volta addosso!/ - Se bruciassero un po' lui/ perché ridesse meglio!/ - Sarebbe la fine che si merita!/ - Quando sarà in prigione scapperà,/ è talmente pieno di scaltrezza!/ - Peggio d'una faina!/ - Non vedete che occhi che à?/ - Perché non lo buttano in un pozzo?/ - Nel cisternone del comune!/ - E ci sono di quelli/ che avrebbero pietà!/ - Bisogna esser roba poco pulita/ per aver compassione/ di questa sorta di persone!

9 Largo! Largo! Largo!/ Ciarpame! Piccoli esseri/ dall'esalazione di lezzo,/ fetido bestiame!/ Ringollatevi tutti/ il vostro sconcio pettegolezzo,/ e che vi strozzi nella gola!/ Largo! Sono il poeta!/ Io vengo di lontano,/ il mondo ò traversato,/ per venire a trovare/ la mia creatura da cantare!/ Inginocchiatevi marmaglia!/ Uomini che avete orrore del fuoco,/ poveri esseri di paglia!/ Inginocchiatevi tutti!/ Io sono il sacerdote,/ questa gabbia è l'altare,/ quell'uomo è il Signore!

Cad. Nietzsche, Guarulhos/Porto Seguro, v.42, n.2, p. 201-222, maio/agosto, 2021. | 209 
Hass, J. e Klein, A. I.

que espera!/ Vá, passa irmão, corre, para aquecer/ a gélida carcaça/ deste velho mundo! ${ }^{10}$ (PALAZZESCHI, 1910, p. 79-80).

Como observa Adele Dei (2002, p. XXXV-XXXVI), o poeta grita, reivindicando de maneira decidida e orgulhosa, a afirmação do ser poeta - "Abram caminho! Sou o poeta!" - e tanto ele quanto o incendiário se opõem abertamente, com bastante agressividade, à repressão do mundo, ao conformismo da multidão, pois objetivam a libertação. Neste sentido, podem ser comparados ao além do homem de Nietzsche, pois estão acima "do bem e do mal" comumente propagado pela moralidade estabelecida; buscam seu potencial absoluto, ao viver de maneira independente e criativa, sem se limitarem às expectativas, desejos ou exigências dos outros em relação a eles.

De acordo com o filósofo alemão, o homem, por meio do autoaperfeiçoamento, deve se superar e tornar-se o além do homem: "Prólogo, 3 - Quando Zaratustra chegou à cidade mais próxima, na margem da floresta, ali encontrou muita gente reunida na praça; pois fora anunciado que um equilibrista andaria na corda. E Zaratustra assim falou à gente: Eu vos ensino o super-homem. $\mathrm{O}$ homem é algo que deve ser superado. Que fizestes para o superá-lo? [...]" (Za/ZA, Prólogo, 3, KSA 4.14) ${ }^{11}$. Assim, com tais palavras, Zaratustra afirma que a humanidade deve ser superada, deve alcançar o ideal da autossuperação - o "além do homem" -, não como recurso metafísico, mas de acordo com as possibilidades humanas.

Para Nietzsche, o ser humano pode transcender a si mesmo por meio do autodomínio, pois tem a capacidade de superar as

$10 \mathrm{Tu}$ mi guardi, senza parlare,/ tu non parli,/ e i tuoi occhi mi dicono:/ uomo, poco farai tu che ciarli./ Ma fido in te!/ T'apro la gabbia va'!/ Guardali, guardali, come fuggono!/ Sono forsennati dall'orrore,/ la paura gli à tutti impazzati./ Potete andare, fuggite, fuggite,/ egli vi raggiungerà!/ [...[/ Non le vedrò più!/ Avrò un urlo di gioia!/ Ci sei passato tu!/ E dopo mi sentirò lambire le vesti,/ le fiamme arderanno/ sotto la mia casa.../ griderò, esulterò,/ m'avrai data la vita!/ Io sono una fiamma che aspetta!/ Va', passa fratello, corri, a riscaldare/ la gelida carcassa/ di questo vecchio mondo!

11 Todas as citações das obras de Nietzsche foram traduzidas por Paulo César de Souza, conforme consta nas referências.

210 | Cad. Nietzsche, Guarulhos/Porto Seguro, v.42, n.2, p. 201-222, maio/agosto, 2021. 
A presença de Friedrich Nietzsche na vida e na produção de Aldo...

limitações da própria condição. Autoaperfeiçoar-se significa ser capaz de aprender com as experiências ou impulsos negativos e não os negar. Seguindo tais princípios, as pessoas psicologicamente fortes e saudáveis, os denominados além do homem, buscam a autoexpansão, vivendo de maneira corajosa.

$\mathrm{O}$ incendiário de Palazzeschi, mesmo estando enjaulado e exposto em praça pública para ser ridicularizado por três dias antes de cumprir sua sentença, mantém a calma e a cabeça erguida:

[...] - Mas nem mesmo mantê-lo nesta jaula!/ - Eles vão fazê-lo morrer de raiva!/ - Morrer! É um cara que não está nem aí!/ - Está mais tranquilo do que a gente!/ - Diria que se diverte./ [...]/ - E como está tranquilo!/ - Não tem medo mesmo!/ - Eu morreria de vergonha!/ - Ficar ali no meio da berlinda!/ - Por três dias!/ - Que vexame!/ - Meu Deus, que cara sinistra!/ - Que olhar malandro! ${ }^{12}$ (Palazzeschi, 1910, p. 70-71).

Ser humilde, obediente, autolimitado, sentir pena e/ou culpa, impedem o ser humano de explorar as várias possibilidades oferecidas pela vida, por isso Nietzsche vai contra princípios basilares do cristianismo e critica as religiões e as filosofias que pregam comportamentos e sentimentos desse tipo.

Para o filósofo, a vida deve estar em constante transformação, ser desafiadora, vivida sem arrependimentos, ser criativa, intensa e arriscada; o ser humano precisa buscar a autossuperação e agir de acordo com a vontade de potência. Em outras palavras, precisa se autorrenovar continuamente, viver como o além do homem. A afirmação da vida deveria ser utilizada para que as tendências dionisíacas e apolíneas fossem combinadas, pois correspondem às dimensões complementares da realidade, sendo, portanto, ambas necessárias. Segundo Nietzsche, a ideia de além do homem está

12 - Ma nemmeno tenerlo in questa gabbia!/ - Lo faranno morire dalla rabbia!/ - Morire! È uno che se la piglia!/ - È più tranquillo di noi!/ - Io dico che ci si diverte./ [...// - Ma come se ne sta tranquillo!/ - Non à mica paura!/ - Io morirei dalla vergogna!/ - Star lì in mezzo alla berlina!/ - Per tre giorni!/ - Che gogna!/ - Dio mio che faccia bieca!/ - Che guardatura da brigante! 
Hass, J. e Klein, A. I.

ligada a uma vida desfrutada com paixão, coragem e decisão por um indivíduo capaz de criar seu próprio estilo, conferindo a sua existência um sentido particular, que deve ser vivido de forma plena e coerente com os princípios por ele estabelecidos.

Da mesma maneira, o personagem de Palazzeschi se mantém firme em suas escolhas, apesar das constantes tentativas de opressão por parte da polícia e da população: "Pode-se ler em seus olhos!/ E saltam faíscas de seus olhos,/ a cem, a cem, a mil!/ Você pode com os olhos/ queimar o mundo inteiro!"13 (Palazzeschi, 1910, p. 76), diz a voz do poeta dirigindo-se ao incendiário.

Contrariando os princípios do cristianismo e criticando as religiões e as filosofias que pregam a humildade, a obediência, a autolimitação, o sentimento de pena e/ou de culpa, Nietzsche cria a figura emblemática do "homem louco", um personagem que anuncia a morte de Deus, afirmando ser esse um dos eventos mais importantes da história:

125. O homem louco - Não ouviram falar daquele homem louco que em plena manhã acendeu uma lanterna e correu ao mercado, e pôs-se a gritar incessantemente: "Procuro Deus! Procuro Deus!"? — E como lá se encontrassem muitos daqueles que não criam em Deus, ele despertou com isso uma grande gargalhada. [...]. O homem louco se lançou para o meio deles e trespassou-os com seu olhar. "Para onde foi Deus?", gritou ele, "já lhes direi! Nós o matamos — vocês e eu. Somos todos seus assassinos! [...] Não ouvimos o barulho dos coveiros a enterrar Deus? Não sentimos o cheiro da putrefação divina? — também os deuses apodrecem! Deus está morto! Deus continua morto! E nós o matamos! Como nos consolar, a nós, assassinos entre os assassinos? O mais forte e mais sagrado que o mundo até então possuíra sangrou inteiro sob os nossos punhais - [...] - e quem vier depois de nós pertencerá, por causa desse ato, a uma história mais elevada que toda a história até então!" Nesse momento silenciou o homem louco, e novamente olhou para seus ouvintes: também eles ficaram em silêncio, olhando espantados para ele. [...] Conta-se também que no mesmo

13 Ti si legge negli occhi!/ Ma ti saltan dagli occhi le faville,/ a cento, a cento, a mille!/ Tu puoi cogli occhi/ bruciare tutto il mondo!

212 | Cad. Nietzsche, Guarulhos/Porto Seguro, v.42, n.2, p. 201-222, maio/agosto, 2021. 
A presença de Friedrich Nietzsche na vida e na produção de Aldo...

dia o homem louco irrompeu em várias igrejas, e em cada uma entoou o seu Requiem aeternam deo. Levado para fora e interrogado, limitava-se a responder: "O que são ainda essas igrejas, se não os mausoléus e túmulos de Deus?" (FW/GC 125, KSA 3.480).

Deus, segundo Nietzsche, foi morto pelos filósofos e cientistas da época em razão de eventos que acabariam por aniquilar as bases dos fundamentos da civilização e da moral cristã; o "homem louco" foi, então, concebido por ele para prenunciar a grande transformação que mudaria radicalmente a organização da sociedade.

Por muito tempo os seres humanos dependeram da crença em Deus para aceitarem os preceitos morais e para que a vida tivesse sentido. No entanto, a ciência e a filosofia, por meio do conhecimento e de resultados de pesquisas, mostraram para a humanidade que não há um poder supremo privilegiando-a, que todas as certezas implicam limitações, restrições e reservas, que tudo pode (e deve) ser contestado, investigado, testado e, portanto, cabe a cada ser encontrar um sentido para a própria vida.

Para o filósofo, as convicções nos impedem de alcançar a verdade; em razão disso desprezava os dogmas e valorizava as opiniões, uma vez que estas podem ser modificadas diante de evidências contrárias. Nietzsche considerava que o autoconhecimento seria a única maneira de se encontrar respostas para as inquietações e sentido para a vida. Nesse sentido, a moralidade deve resultar da busca interior e não ser imposta por uma doutrina ou instituição. $\mathrm{O}$ autoconhecimento revela a motivação humana mais básica, ou seja, a vontade de potência. Em outras palavras, a força motivacional mais primitiva do ser humano, da qual derivam todas as outras motivações, seria o desejo de liberar esse potencial, a busca por superioridade, fortalecimento, crescimento e expansão, mediante a vontade potência. Felicidade significaria, então, para o filósofo, ampliação da vontade de potência individual, autodomínio e controle 
Hass, J. e Klein, A. I.

sobre o próprio destino; significaria não se limitar pela moralidade convencional, significaria agir como o além do homem.

O Deus de Palazzeschi, assim como aponta Curi (2007, p. 55), é "totalmente humanizado e pelo qual o escritor demonstra nutrir simpatia sem, porém, expressar qualquer reverência". Ao humanizar Deus, de certo modo, o autor acaba por matá-lo, pois o aproxima de todas as características humanas, excluindo, com isso, aquelas divinas. Apesar de não estarmos analisando Il Controdolore, vale a pena mostrar como Palazzeschi descreve Deus em seu manifesto:

Se eu o imagino como homem, não o vejo nem maior nem menorzinho do que eu. Um homenzinho sempre de estatura mediana, sempre de meiaidade, sempre de médias proporções, que me surpreende por apenas uma coisa: que, enquanto o considero hesitante e assustado, ele me olha morrendo de rir. Seu rostinho redondo ri divinamente como incendiado por uma risada infinita e eterna, e sua barriguinha trêmula, trêmula naquela alegria. [...] Na minha opinião, o universo está centrado em sua boca divina, em uma eterna motriz risada. Ele não criou, não, tenham certeza, para um fim trágico, melancólico ou nostálgico; ele criou porque isso o divertia. [...] Ele trabalhou para manter sua alegria nutrida e oferecê-la às suas dignas criaturas. $\mathrm{E}$ vocês entenderão bem que, para que todos se divirtam eternamente, são necessários curiosos e eternos espetáculos! ${ }^{14}$ (Palazzeschi, 2004, p. 1221).

Além de imaginar Deus como um homem de estatura mediana, de meia-idade e de médias proporções, Palazzeschi se vale do diminutivo com o intuito de atenuar ainda mais suas proporções normais e sua força - "o considero hesitante e assustado" - e

14 Se io me lo figuro uomo, non lo vedo né più grande né più piccino di me. Un omettino di sempre media statura, di sempre media età, di sempre medie proporzioni, che mi stupisce per una cosa soltanto: che mentre io lo considero titubante e spaventato, egli mi guarda ridendo a crepapelle. La sua faccettina rotonda divinamente ride come incendiata da una risata infinita ed eterna, e la sua pancina tremola, tremola in quella gioia. [...] Secondo me, nella sua bocca divina si accentra l'universo in una eterna motrice risata. Egli non à creato no, rassicuratevi, per un tragico, o malinconico, o nostalgico fine; à creato perché ciò lo divertiva. [...] Egli lavorò per tenere alimentata la gioia sua ed offrirne alle sue degne creature. E comprenderete bene che per divertirsi tutti in eterno, ce ne vogliono dei curiosi ed eterni spettacoli!

214 | Cad. Nietzsche, Guarulhos/Porto Seguro, v.42, n.2, p. 201-222, maio/agosto, 2021. 
A presença de Friedrich Nietzsche na vida e na produção de Aldo...

de mostrar um teor afetivo. $\mathrm{O}$ incendiário, por sua vez, por meio do incêndio, revela a todos do vilarejo sua vontade de potência, alcançando, por conseguinte, o autoconhecimento e, por isso, é comparado pelo poeta a Deus:

Quando você queima/ você não é mais o homem,/ você é Deus!/ Sinto um arrepio correndo em minhas veias./ Gostaria de ver você queimando,/ enquanto olha suas chamas;/ [...] Lindo, lindo, lindo... e Santo!/ Santo! Santo!/ Santo quando pensa queimar./ Santo quando queima,/ Santo quando olha para elas/ suas chamas santas! ${ }^{15}$ (Palazzeschi, 1910, pp. 76-77).

Isso porque, na visão do poeta, o incendiário controla seu próprio destino, não se limita pela moralidade convencional e, portanto, age como o além do homem.

Retornando ao Deus "controdoloriano", Palazzeschi diz que "seu rostinho redondo ri divinamente como incendiado por uma risada infinita e eterna, e sua barriguinha trêmula, trêmula naquela alegria”. Na opinião do autor, como já apontado, "o universo está centrado em sua boca divina, em uma eterna motriz risada" e Deus "criou porque isso o divertia".

John Lippitt. em seu artigo Nietzsche, Zarathustra and the status of laughter (1992), afirma que, para Nietzsche, “o riso está longe de ser um fenômeno trivial e frívolo. Em vez disso, desempenha um papel importante em toda sua visão de mundo"16 (p. 39). O estudioso sustenta que ignorar a contribuição de Nietzsche para a filosofia do riso e do humor seria um descuido importante, pois acredita que ele tenha atribuído ao riso um status superior ao dado por qualquer outro filósofo.

15 Quando tu bruci/ tu non sei più l'uomo,/ il Dio tu sei!/ Mi sento correr per le vene un brivido./ Ti vorrei vedere quando abbruci,/ quando guardi le tue fiamme; [...]/ Bello, bello, bello..... e Santo!/ Santo! Santo!/ Santo quando pensi di bruciare./ Santo quando abbruci,/ Santo quando le guardi/ le tue fiamme sante!

16 For Nietzsche, laughter is far from being a trivial, frivolous phenomenon. Rather, it plays an important role in his entire world-view. 
Hass, J. e Klein, A. I.

Após fazer uma análise sobre a função e a importância do riso nas quatro partes de Assim falava Zaratustra, Lippitt (1992, p. 45) chega à ideia de que "o que Zaratustra aprendeu, a habilidade vital da qual depende sua liberação e autossuperação, é a habilidade de rir de si mesmo "como um homem deve rir" "17. Nesse sentido, ainda em suas palavras, "uma pessoa será realmente capaz de rir de si mesmo se aceitar que a vida é, em um sentido absoluto, sem sentido, e rir da risada desta constatação, em vez de recorrer a algum tipo de "má fé""ls.

Seguindo uma concepção muito similar a essa, Palazzeschi afirmará, posteriormente, em um texto publicado na revista Lacerba (1915, p. 70): “os homens que levam os outros a sério me dão pena, aqueles que se levam a sério me fazem gargalhar"19. Assim como em Nietzsche, a crítica à moral é feita mediante a leveza, o riso e o jogo. Em outras palavras, a transvaloração de todos os valores que o filósofo desejava deve passar necessariamente por um riso profundo e impiedoso contra a moralidade convencional, como aponta Tiago Medeiros de Oliveira (2018). Não nos parece diversa a risada que se apresenta de várias maneiras nas obras de Palazzeschi.

No pensamento de Palazzeschi, o riso, em suas diversas formas, representa uma paródia da vida por meio da inversão de valores da realidade, pois nega a dor por meio da zombaria, definindo e multiplicando a vontade de viver, independentemente das adversidades da vida. O riso, segundo o autor, é fundamental para e existência humana e, por isso, é recomendado: a força da risada rompe com o pessimismo, destrói todos os padrões, fundamenta uma

17 What Zarathustra has learned, the vital skill upon which his liberation and self-overcoming is dependent, is the ability to laugh at himself 'as a man ought to laugh'.

18 One can genuinely be said to be capable of laughing at oneself if one can accept Nietzsche's claim that one's life is, in an absolute sense, pointless, and laugh the laughter of the height at this realization, rather than resorting to some sort of 'bad faith'.

19 Gli uomini che prendono sul serio gli altri mi fanno compassione, quelli che prendono sul serio sé stessi mi fanno sganasciare dalle risa.

216 | Cad. Nietzsche, Guarulhos/Porto Seguro, v.42, n.2, p. 201-222, maio/agosto, 2021. 
A presença de Friedrich Nietzsche na vida e na produção de Aldo...

nova moral e estabelece novos princípios; o riso é, portanto, símbolo e expressão da vontade de potência. Não à toa o autor afirmava:

Se acreditam que seja profundo aquilo que comumente se entende por sério, vocês são superficiais. É preciso habituar-se a rir de tudo aquilo pelo que habitualmente se chora [...]. O homem só pode ser considerado seriamente quando ri. [...] nada é profundamente triste, tudo é alegre. [...]É preciso educar nossos filhos ao riso"20 (Palazzeschi, 2004, p. 1224). Assim, não por acaso, quando questionado, o incendiário "respondeu rindo/ que queima por divertimento ${ }^{21}$ (PALAZZESCHI, 1910, p. 72).

Por esses motivos Hirdt (2007, p. 33) afirma que "a risada está no rosto e no ouvido de Palazzeschi, com uma estrutura bem articulada, o juiz de tudo aquilo que existe, [...] toma o partido de uma forma de vida sustentável entre horror e diversão"22.

Assim, como pudemos perceber, o pensamento de Nietzsche não influenciou apenas as obras de Palazzeschi, mas, também, seu estilo de vida. Como apontado ao longo deste estudo, o poeta e escritor, nas palavras de Tellini, tendo vivenciado um processo de reflexão e, a partir daí, começado a ignorar o julgamento dos outros, a ridicularizar os boatos e a libertar-se do conformismo, foi capaz de passar "(são palavras suas) do 'desespero' à 'alegria"'23 (TELLINI, 2020, p. 84), como igualmente fazem os além do homem nietzschianos.

Os cinco aspectos essenciais que aparecem nas obras de Palazzeschi, apontados por Tellini, como o cômico, a ironia, a paródia, que rompem as barreiras das ideias vigentes e libertando

20 Se credete che sia profondo ciò che comunemente s'intende per serio siete dei superficiali. Bisogna abituarsi a ridere di tutto quello di cui abitualmente si piange [...]. L'uomo non può essere considerato seriamente che quando ride. [...] nulla è triste profondamente, tutto è gioioso. [...] Bisogna educare al riso i nostri figli.

21 à risposto ridendo/ che brucia per divertimento.

22 la risata è nel volto e nell'udito di Palazzeschi, con una struttura ben articolata, il giudice di tutto ciò che esiste. [...] si schiera a favore di una forma di vita sostenibile tra orrore e divertimento.

23 (sono parole sue) dalla «disperazione» all'«allegria».

Cad. Nietzsche, Guarulhos/Porto Seguro, v.42, n.2, p. 201-222, maio/agosto, 2021. | 217 
Hass, J. e Klein, A. I.

do conformismo; o ser "diferente", que adquire centralidade e ajuda no enfrentamento dos diversos obstáculos para a integração na sociedade; a positividade do "diferente", bastante valorizada; a ironia e a promoção do "diferente" como ferramentas para atribuir valor e significado ao "dom" da vida, aos elementos simples, comuns, sinceros, inocentes da existência e, por fim, aceitação da vida como passageira e da morte com serenidade poderiam, a nosso ver, ser ancorados, em parte, na leitura e interpretação que o autor faz de conceitos nietzschianos.

Ademais, Tellini menciona uma carta em que Aldo Palazzeschi responde a algumas perguntas feitas pela poetisa e tradutora Maria Luisa Belleli (Veneza, 4 de setembro de 1970). Nela, em relação ao Controdolore, o escritor nega certa "influência" do manifesto L'antitradition futuriste (1913), de Apollinaire, mas reconhece sua "dívida" com Nietzsche: "Na realidade, entre os pouquíssimos livros que li naquela época (e também posteriormente), tinha lido Nietzsche e fiquei muito apaixonado, encontrei nele o pão para a luta da minha alma de cristão (Palazzeschi-Belleli, pp. 129-131)"'24 (Tellini, 2004, p. 1660).

Ao abandonar a vida de ator, sem, no entanto, afastar-se do teatro em suas produções, o autor aderiu ao Futurismo. Poucos anos após a clamorosa recepção por parte dos vanguardistas, Palazzeschi declarou, em 1914, na revista Lacerba, seu rompimento com Marinetti e com o Futurismo - "A partir de hoje eu não tenho nada mais a ver com o movimento futurista. Se F.T. Marinetti se servir do meu nome para o seu movimento o fará abusivamente" ${ }^{95}$ (Palazzeschi, 2004, p. CXXXVIII) -, pois sua personalidade independente e sua

24 «Effettivamente fra i pochissimi libri da me letti a quel tempo (e anche al tempo di poi) avevo letto Nietzsche e mi aveva molto appassionato, vi avevo trovato dentro il pane per la lotta del mio animo di cristiano» (Palazzeschi-Belleli, pp. 129-131).

25 Da oggi io non ho più nulla a che fare con il movimento futurista. Se F.T. Marinetti si servisse del mio nome per il suo movimento lo farebbe abusivamente.

218 | Cad. Nietzsche, Guarulhos/Porto Seguro, v.42, n.2, p. 201-222, maio/agosto, 2021. 
A presença de Friedrich Nietzsche na vida e na produção de Aldo...

posição pacifista não lhe permitiam concordar com a campanha dos futuristas a favor da guerra.

Nesse sentido, não foi futurista, nem crepuscular e nem sequer Liberty, apesar de ser a vanguarda artística que, no início do século $\mathrm{XX}$, exerceu forte influência nos artistas que buscavam novidades. Palazzeschi, na verdade, foi um grande solitário, um anarquista da poesia, da literatura e da vida. Reagiu ao egotismo dos mestres dos séculos XIX e XX por meio de sua forte marca estilística que revela sua autonomia em relação às tendências ou movimentos artísticos e literários à época vigentes e, muitas vezes, foi um autor capaz de propor novidades que apontaram para outros caminhos nas produções artísticas do momento.

As técnicas de escrita por ele utilizadas, tais como o tom impessoal, átono, amorfo, transformado, em vários momentos, em nênia infantil ou, muito mais frequentemente, em rima teatral; a simplificação da linguagem e da sintaxe; a ironia; os dialetos e a presença de elementos musicais, conferem leveza a seus textos, além de demonstrar o desprezo pela tradição e pela normalização linguística e gramatical, em especial no que se refere à utilização da linguagem coloquial e do coralismo. Com isso, segue de forma absolutamente coerente sua declaração de poética: a risada, o paradoxo e a ironia são armas contra a tradição poética e o "bom gosto" do público em geral.

Telê Ancona Lopez demostra a importância que os textos lidos pelos escritores têm para a compreensão das escolhas feitas por eles em suas produções literárias; suas leituras colaboram para a criação, estão presentes implícita ou explicitamente em suas obras e, a marginália, "as notas marginais que selecionam trechos e palavras" (Lopez, 2007, p. 33), substancializa esta apropriação criativa:

Nas influências reconhecidas, nas leituras declaradas, na presença de determinadas obras na biblioteca de um escritor, nas notas autógrafas à margem de leituras ou em folhas apensas e em todas as formas e feições do trabalho nesse espaço, insinuam-se matrizes, instaurando o diálogo que 
Hass, J. e Klein, A. I.

traz a intertextualidade da criação. As matrizes são principais quando se ligam ao modo de formar; quando textos ou elementos de um texto - temas, motivos, sequências, cenas, personagens, estilo, tratamento do tempo e do espaço etc. - enraízam a (re)criação que se afirma com originalidade e autonomia ao integrar outro contexto. (Lopez, 2007, p. 33)

A produção rica e intensa de Palazzeschi, em parte influenciada pela filosofia de Nietzsche, foi importante para a literatura italiana e cobriu longo período: teve início com as poesias de I Cavalli bianchi (1905) e concluiu-se com Via delle cento stelle (1972). Foram sessenta e sete anos de produção, com a publicação de treze livros de poesias I cavalli bianchi (1905); Lanterna (1907); Poemi (1909); L'Incendiario (1910); L'Incendiario 1905-1909 (1913); Poesie 1904-1909 (1925); Piazza San Pietro (1945); Difetti 1905 (1947); Viaggio sentimentale (1955); Schizzi italofrancesi (1955); Cuor mio (1968); La passeggiata (1971); Via delle cento stelle 1971-1972 (1972) -, dez romances :riflessi (1908); Il Codice di Perelà (1911); La Piramide (1926); Sorelle Materassi (1934); I fratelli Cuccoli (1948); Roma (1953); Il Doge (1967); Stefanino (1969); Storia di un'amicizia (1971); Interrogatorio della Contessa Maria (póstumo, 1988) -, quatro contos - Il Re bello (1921); Il palio dei buff. Novelle (1937); Bestie del 900 (1951); Il buffo integrale (1966), além de prosas, crônicas, memórias - Due imperi... mancati (1920); Stampe dell'800 (1932); Nell'aria di Parigi (1945); Tre imperi... mancati. Cronaca 1922-1945 (1945); Scherzi di gioventù (1956); Vita militare (1959); Il piacere della memoria (1964); Ieri, oggi e... non domani (1967), além de outros inúmeros textos, em forma de epístolas, escritos esparsos e traduções, que merecem ser conhecidos e estudados. 
A presença de Friedrich Nietzsche na vida e na produção de Aldo...

\title{
The presence of Friedrich Nietzsche within the life and work of Aldo Palazzeschi
}

\begin{abstract}
Writers' libraries often provide details in relation to their productions, as they end up revealing and broadening the understanding of some influences that, in general, would not be clear in their works; they are often inspirations that also come from the historical moment, especially in those who lived in times of profound changes. This article aims to show the influence of Friedrich Nietzsche in life and in part of the works of Aldo Palazzeschi produced and published in the first half of the 20th century.

Keywords: Aldo Palazzeschi, Friedrich Nietzsche, Italian Futurism, Biography, Writers' library, Influence.
\end{abstract}

\section{Referências}

BERGMAN, Pär. Breve panorama do movimento futurista (desde sua fundação até a Grande Guerra). Tradução Júlio Bernardo Machinski. Revista Ágora, Vitória, n. 20, p. 215-243, 2014.

CECCHI, Emilio; SAPEGNO, Natalino. Benedetto Croce a Emilio Cecchi, 11 dicembre 1911. In: Storia della letteratura italiana. Milano: Garzanti, 19651969, Vol. IX, p. XIV.

CURI, Fausto. Palazzeschi e Nietzsche. In: JUNG, Willi; TELLINI, Gino. Palazzeschi Europeo. Atti del Convegno Internazionale di Studi Bonn-Colonia, 30-31 maggio 2005. Firenze: Società Editrice Fiorentina, 2007, pp. 39-64.

DEI, Adele. Giocare col fuoco. Storia di Palazzeschi Poeta. In: DEI, Adele (a cura di). Palazzeschi. Tutte le poesie. Milano: Mondadori, I Meridiani, 2002.

HIRDT, Willi. Pirandello e Palazzeschi. In: JUNG, Willi; TELLINI, Gino. Palazzeschi Europeo. Atti del Convegno Internazionale di Studi Bonn-Colonia, 30-31 maggio 2005. Firenze: Società Editrice Fiorentina, 2007, pp. 25-38.

HOBSBAWM, Eric John Ernest. A era dos impérios 1875-1914. Tradução Sieni Maria Campos e Yolanda Steidel de Toledo. Rio de Janeiro: Paz e Terra, 1988.

LIPPITT, John. Nietzsche, Zarathustra and the status of laughter. British Journal of Aesthetics, v. 32, n. 1, pp. 39-49, January 1992. 
Hass, J. e Klein, A. I.

LOPEZ, Telê Ancona. A criação literária na biblioteca do escritor. Ciência e Cultura, São Paulo, v. 59, n. 1, p. 33-37, março de 2007.

MAGHERINI, Simone. MANGHETTI, Gloria. Scherzi di gioventù e d'altre età: album Palazzeschi (1885-1974). Firenze: Pagliai Polistampa, 2001.

NIETZSCHE, F. Sämtliche Werke. Kritische Studienausgabe in 15 Bänden. Herausgegeben von Colli und Montinari. Berlin/ München: Walter de Gruyter/ DTV, 1988.

. Humano, demasiado humano. Um livro para espíritos livres. Tradução Paulo César de Souza. São Paulo: Companhia de Bolso, 2005.

. Assim falou Zaratustra. Um livro para todos e para ninguém. Tradução Paulo César de Souza. São Paulo: Companhia das Letras, 2011.

. A Gaia Ciência. Tradução Paulo César de Souza. São Paulo: Companhia das Letras, 2012.

OLIVEIRA, Tiago Medeiros de. Nietzsche: um riso filosófico para além do bem e do mal. 126 p. Dissertação, Mestrado em Filosofia, Universidade Federal da Paraíba, 2018.

PALAZZESCHI, Aldo. L'Incendiario. Col rapporto sulla vittoria futurista di Trieste. Milano: Edizioni Futuriste di Poesia, 1910, pp. 69-80.

. Spazzatura. Lacerba, III, 9, p.70, 28 febbraio 1915.

. Il Controdolore. In: TELLINI, Gino. (Org.). Aldo Palazzeschi. Tutti i Romanzi. Milano: Mondadori, 2004, pp. 1221-1232.

TELLINI, Gino. Le biografie degli autori. In: TELLINI, Gino; RUOZZI, Gino. (a cura di). Didattica della letteratura italiana. Riflessioni e proposte applicative. Firenze: Le Monnier Università, 2020, pp. 73-84.

. Notizie sui testi [Allegati]. In: TELLINI, Gino. (a cura di). Tutti $i$ Romanzi. Milano: Mondadori, I Meridiani, 2004, p. 1660.

Enviado: 03/10/2020

Aceito: $21 / 12 / 2020$

222 | Cad. Nietzsche, Guarulhos/Porto Seguro, v.42, n.2, p. 201-222, maio/agosto, 2021. 